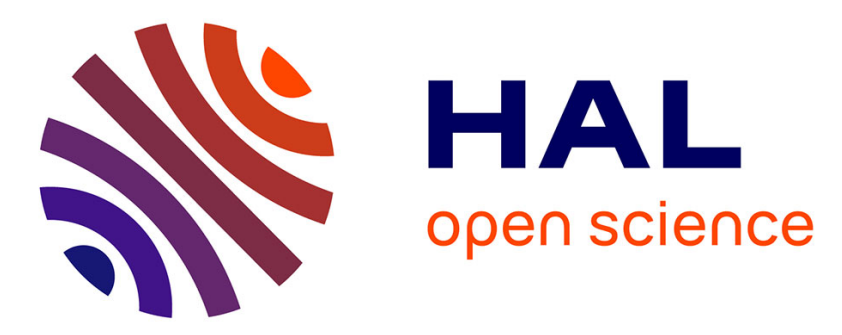

\title{
Actual vs optimal fetal hematocrit measured with punctures of cord blood in utero: Relationship with umbilical artery resistance
}

Jean-Frédéric Brun, Pierre Boulot, Emmanuelle Varlet-Marie

\section{- To cite this version:}

Jean-Frédéric Brun, Pierre Boulot, Emmanuelle Varlet-Marie. Actual vs optimal fetal hematocrit measured with punctures of cord blood in utero: Relationship with umbilical artery resistance. Clinical Hemorheology and Microcirculation, 2017, 64 (4), pp.789 - 797. 10.3233/CH-168016 . hal-01803683

\section{HAL Id: hal-01803683 \\ https://hal.umontpellier.fr/hal-01803683}

Submitted on 9 Mar 2020

HAL is a multi-disciplinary open access archive for the deposit and dissemination of scientific research documents, whether they are published or not. The documents may come from teaching and research institutions in France or abroad, or from public or private research centers.
L'archive ouverte pluridisciplinaire HAL, est destinée au dépôt et à la diffusion de documents scientifiques de niveau recherche, publiés ou non, émanant des établissements d'enseignement et de recherche français ou étrangers, des laboratoires publics ou privés. 


\title{
Actual vs optimal fetal hematocrit
}

\section{measured with punctures of cord blood in utero: Relationship with umbilical artery resistance}

Jean-Frédéric Brun ${ }^{\mathrm{a}, *}$, Pierre Boulot ${ }^{\mathrm{b}}$ and Emmanuelle Varlet-Marie ${ }^{\mathrm{c}, \mathrm{d}}$ ${ }^{a} U M R$ CNRS 9214-Inserm U1046, «Physiopathologie \& Médecine Expérimentale du Cour et des Muscles - PHYMEDEXP», Unité d'Explorations Métaboliques (CERAMM), Université de Montpellier, Département de Physiologie Clinique, Hópital Lapeyronie CHU Montpellier, France bervice de Gynécologie Obstétrique, Hópital Arnaud de Villeneuve, CHU Montpellier, France ${ }^{\mathrm{c}}$ Institut des Biomolécules Max Mousseron (IBMM) UMR CNRS 5247, Université de Montpellier, Ecole Nationale Supérieure de Chimie de Montpellier, France ${ }^{\mathrm{d}}$ Laboratoire de Biophysique \& Bio-Analyses, Faculté de Pharmacie, Université de Montpellier, France

\begin{abstract}
Physiological studies on fetal blood in narrow glass tubes have suggested that fetal optimal hematocrit (hct) might be as high as $60 \%$. A theoretical 'ideal' het can also be predicted with a theoretical curve of hematocrit/viscosity (h/ $\eta$ ) ratio vs het constructed with Quemada's model. We used the database of one of our previous papers on fetal hemorheology to reinterpret its results with this concept. A series of 28 intrauterine cord punctures (between 19 and 33 weeks gestation) with doppler measurements of resistance in umbilical arteries was studied. The theoretical 'optimal hematocrit' was well correlated to actual $(r=0.857, p<0.01)$ but systematically lower (Bland-Altman plot $+12.1[8.52-15.7])$ than the actual one. Umbilical artery resistance index is correlated with actual hematocrit $(r=0.407, p<0.05)$, the discrepancy between ideal and actual $(r=-0.542, p<0.05)$ but not predicted ideal hematocrit, suggesting that the discrepancy between ideal and actual may reflect an adaptative decrease aiming at reducing vascular resistance. These findings indicate that prediction of ideal hematocrit with Quemada's equation makes sense in fetal blood, and suggest that a 'viscoregulatory mechanism' maintains hematocrit below this theoretical value in order to avoid excess vascular resistance.
\end{abstract}

Keywords: Blood viscosity, hematocrit, exercise, fetus, erythrocyte deformability

\section{List of symbols}

$\mathrm{RBC}$ red blood cell

\section{Introduction}

The hemorheological properties of blood in the normal fetus have been the matter of several studies over the last decades $[1,3,4,7,8,12,14,16,17,21]$. These studies evidenced that the fetus has a high

${ }^{*}$ Corresponding author: Jean-Frédéric Brun, UMR CNRS 9214-Inserm U1046, «Physiopathologie \& Médecine Expérimentale du Cœur et des Muscles - PHYMEDEXP», Unité d'Explorations Métaboliques (CERAMM), Université de Montpellier, Département de Physiologie Clinique, Hópital Lapeyronie CHU Montpellier, France. Tel.: +33 467338284; Fax: +33 467338986; E-mail: j-brun@chu-montpellier.fr. 
hematocrit, a decreased red cell deformability, and very low values of erythrocyte aggregation and plasma viscosity. Therefore this specific pattern associates properties that can lead to an increase in blood viscosity, and others that can do the opposite. During the early nineties, intrauterine venepunctures [5] allowed our team to describe the physiological evolution of fetal blood viscosity during the intrauterine life and to evidence a correlation between fetal blood viscosity and hemodynamic data obtained by doppler just before the puncture [6]. Such an invasive approach of fetal blood is no longer used today and it would be impossible to replicate this study, but the databases obtained at that time are still available.

In various fields of medicine the issue of optimal hematocrit [9] is a matter of numerous studies that have renewed its interest [23], and it was attractive to investigate also this issue in fetuses.

The surprisingly high value of hematocrit found in newborns has raised the question of how fetuses could cope with a so high hematocrit. Linderkamp investigated thus the issue of optimal hematocrit in fetal blood in vitro in narrow glass tubes, and found with this in vitro approach values of optimal hematocrit around $40 \%$ in 500-pm tubes, around 52\% in 100-pm tubes, and around 60\% in 50-pm tubes [18].

In both sedentary and exercise-trained adults we have reported that Quemada's equation [20] provided a prediction of a theoretical optimal hematocrit that fairly predicted the actual one, but that sedentary individuals had an actual value of hematocrit lower than the ideal one, the discrepancy between ideal and actual being related to red cell rigidity and blood pressure, and representing thus a 'reserve' subjects in order to cope with the need of increasing blood viscosity factors in case of exercise without impairing $\mathrm{O}_{2}$ supply to tissues.

We applied this calculation to our previously obtained database of fetal blood viscosity measurements obtained from intrauterine cord blood samplings, in order to calculate the theoretical optimal hematocrit, to compare it with the actual one, and to investigate whether this discrepancy is related to hemodynamic parameters.

\section{Subjects and methods}

\subsection{Study subjects}

We used the database of a previous paper on fetal hemorheology to reinterpret its results in order to test prediction of hematocrit [6].

Fetuses included in this study underwent a cord venepuncture for the detection of genetic abnormalities and/or recent infection by rubella or toxoplasmosis. Cordocentesis was performed in utero during pregnancy as previously reported [5]. The method allowed an ambulatory sampling during a hospital visit performed in an operating room with surgical preparation of the abdomen. No premedication (e.g. maternal sedation) was administered. Bladder filling was unnecessary. The ultrasound device was a $3.5 \mathrm{MHz}$ sectorial transducer (Combison Kretz 320) manipulated through a sterile bag. After local anesthesia (1 per cent xylocaine), a 22.5 gauge needle fixed on a syringe was introduced in the plane of the ultrasound section through the abdominal wall, the uterine wall, the membranes, into the amniotic cavity, and finally into the umbilical cord. The 22.5 gauge needle was chosen in order to reduce cord bleeding when the needle was withdrawn. Fetal blood was aspirated after changing the syringe in order to avoid contamination of samples with maternal blood or amniotic fluid. The duration of funicular bleeding was noted at the withdrawal of the needle. Two hours after sampling, patients were again examined ultrasonographically. Preventive antibiotic treatment consisting of $2 \mathrm{~g}$ of cefotaxime daily was administered for 5 days, as well as an injection of anti-D gamma globulin if the mother was Rh-negative and fetus Rh-positive. Two methods were used for verifying purity of blood samples: the 
Kleihauer test and the measurement of the mean corpuscular volume on a Coulter Counter S Plus II. During the study period, samplings were performed by the same obstetrician and ultrasound guidance was performed by the same specialist.

Pathologic cases (malformations, fetal distress) were excluded from the study. Finally, a group of 119 'normal' fetuses was constituted. Fetuses were studied between 18 and 39 week's gestation. Twelve fetuses were studied between 18 and 21 wk, 21 between 22 and 23, 21 between 24 and 25, 15 between 26 and 27, 16 between 28 and 29, 10 from 30 to 31, 11 from 32 to 33, 5 from 34 to 35 and 8 between 36 and 39 wk. At the same time, maternal blood was also drawn (just before the cord puncture).

\subsection{Doppler measurements}

Arterial resistance index of Pourcelot [19] was calculated from Doppler waveform analysis as the difference between systolic and diastolic velocity index divided by the systolic index. This index was calculated in this study in the umbilical artery and in uterine maternal artery, just before the puncture.

\subsection{Laboratory measurements}

Blood was collected into potassium EDTA. In fetuses, only 2 to $3 \mathrm{ml}$ were drawn, while in mothers this volume was $7 \mathrm{ml}$. Measurements were performed within two hours after venepuncture. Hematocrit (packed cell volume) was evaluated by a microhematocrit technique on a Hettige autocrit centrifuge. Blood viscosity and plasma viscosity were measured at very high shear rate $\left(\gamma=1000 \mathrm{~s}^{-1}\right)$ with a micro-method. Measurements were performed on the MT90 falling ball viscometer (Medica-test, 37 rue de l'Ermitage F-86280 Saint Benoit) [11, 13]. We used for control quality and calibration a more sophisticated viscometer which needed unfortunately too much blood and could not be employed for fetal blood. The coefficient of variation of this method ranges between 0.6 and $0.8 \%$ (10 repetitive measurement of the same sample). The results of viscometric measurements were expressed as apparent viscosity at native hematocrit $\eta \mathrm{b}$, viscosity for corrected hematocrit $45 \% \eta 45$, and RBC rigidity index 'Tk'. Correction of blood viscosity for hematocrit was calculated according to Quemada's equation [20].

$$
\eta \mathrm{b}=\eta \mathrm{pl}(1-1 / 2 \mathrm{k} \cdot \mathrm{h})^{-2}
$$

where $\eta \mathrm{pl}$ is plasma viscosity, h hematocrit, and $\mathrm{k}$ a structural parameter of blood viscosity which depends at high shear rate on RBC flexibility. A viscometric index 'Tk' of red cell rigidity (as reflected by shear-induced erythrocyte elongation) was calculated from this viscometric measurement according to Dintenfass [10]. 'Tk' is given by the following equation:

$$
\mathrm{Tk}=\left(\eta \mathrm{r}^{0.4}-1\right) /\left(\eta \mathrm{r}^{0.4} \cdot \mathrm{h}\right)
$$

where $\eta \mathrm{r}$ is relative blood viscosity (i.e. $\eta \mathrm{b} / \eta \mathrm{pl}$ ). The ' $\mathrm{k}$ ' index of $\mathrm{RBC}$ rigidity was also calculated according to Quemada [20]:

$$
\mathrm{k}=2 \cdot\left(1-\eta \mathrm{r}^{-0.5}\right) \cdot \mathrm{h}^{-1}
$$

Quality control of the measurements performed with the MT90 falling ball viscometer was regularly made with the Carrimed rheometer which allows a precise measurement of blood viscosity over a wide variety of shear rates (from less than 0.1 up to $2000 \mathrm{~s}^{-1}$ ). This latter device was not used in the study because it needs more blood sample volume than available from fetuses. 
RBC aggregation in fetal blood drawn in utero was assessed with the Myrenne aggregometer [22] which gives two indices of RBC aggregation: ' $\mathrm{M}$ ' (aggregation during stasis after shearing at $600 \mathrm{~s}^{-1}$ ) and 'M1' (facilitated aggregation at low shear rate after shearing at $600 \mathrm{~s}^{-1}$ ).

\subsection{Prediction of the theoretical optimal hematocrit and hematocrit viscosity ratio}

$$
\mathrm{h} / \eta=\eta /\left[\eta_{\mathrm{p}}(1-1 / 2 \mathrm{k} \phi)^{-2}\right]
$$

The hematocrit corresponding to the top of this curve was considered as the "theoretical optimal hematocrit". The highest value of $h / \eta$ (the top of the curve) was considered as the optimal $h / \eta$.

\subsection{Statistics}

Correlations were performed using the method of least squares. Significance was defined as $p<0.05$.

\section{Results}

Presentation of viscosity measurements throughout intra uretine life can be found in our preceding paper [6]. Briefly, whole blood viscosity at native hematocrit measured at high shear rate exhibits a highly significant progressive increase during the intrauterine life $(p<0.01)$. This increase is first explained by a gradual increase in hematocrit between 12 and $36 \mathrm{wk}(p<0.05)$, from an average of 33\% to $40 \%$. However when corrected for hematocrit viscosity $(\eta 45)$ still increases very significantly during the period of the intrauterine life $(p<0.01)$. This is due to the Dintenfass' 'Tk' RBC rigidity index which undergoes a progressive increase during the intrauterine life $(p<0.05)$. Plasma viscosity $\eta p l$ remains constant during the intrauterine life at an average value of $1.18 \pm 0.01 \mathrm{mPa} . \mathrm{s}$. The $\mathrm{h} / \eta$ ratio remains constant in fetal blood during the intrauterine life at an average value of $18.84 \pm 0.27 \mathrm{mPa}^{-1} . \mathrm{s}^{-1}$. The $\mathrm{RBC}$ aggregation index ' $\mathrm{M}$ ' before $32 \mathrm{wk}$ gestation remains almost equal to zero arbitrary units (mean value: $0.04 \pm 0.01)$. However, at $32-33 \mathrm{wk}$, they begin to slowly increase $(p<0.05)$ until delivery. The $\mathrm{RBC}$ aggregation index ' $\mathrm{M} 1$ ' is somewhat higher and remains constant during all the pregnancy at $2.98 \pm 0.26$.

On Fig. 1 we show the theoretical curve of $h / \eta$ ratio that yields a theoretical optimal $h / \eta$ of $16.98 \pm 0.5$ $\mathrm{mPa}{ }^{-1} \cdot \mathrm{s}^{-1}$ while the actual average value in the sample investigated is $18.48 \pm 0.8 \mathrm{mPa}^{-1} \cdot \mathrm{s}^{-1}$. Therefore the actual $\mathrm{h} / \eta$ is slightly higher than the theoretical $(p<0.05)$. Similarly the model yields a value of ideal hematocrit of: $45.31 \pm 0.71 \%$ which is much higher than the actual one $30.52 \pm 2.26(p<0.001)$. Figures 2 and 3 show the agreement between model-derived and actual values of respectively $h / \eta$ ratio and hematocrit.

Figure 4 shows that the doppler-derived umbilical artery resistance index (Pourcelot index) is correlated with actual hematocrit, but not with its theoretical 'optimal value' and that the discrepancy theoretical-optimal hematocrit is negatively correlated to this umbilical arterial resistance.

As shown on Fig. 5, the discrepancy between actual and theoretical values of hematocrit is positively correlated to whole blood viscosity $(r=0.800 p<0.01)$ and negatively correlated to red cell rigidity index ' $\mathrm{k}$ ' $(r=-0.908, p<0.01)$.

Figure 6 shows that there is a negative correlation between red cell rigidity and the umbilical artery resistance index $(r=-0.565, p<0.05)$. 


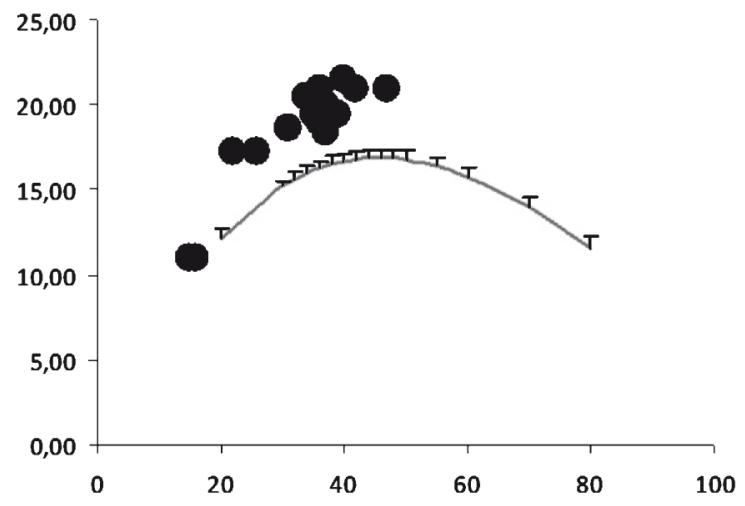

Fig. 1. Theoretical curve of the $\mathrm{h} / \eta$ ratio that gives a theoretical optimal value of at $16.98 \pm 0.5 \mathrm{mPa}^{-1} . \mathrm{s}^{-1}$ and a theoretical optimal value of hematocrit at $45.31 \pm 0.71 \%$. Actual values are shown on the figure (full circles) and it can be seen on the picture that the actual $\mathrm{h} / \eta$ is slightly higher than the theoretical and that the actual hematocrit is markedly lower than the actual one.
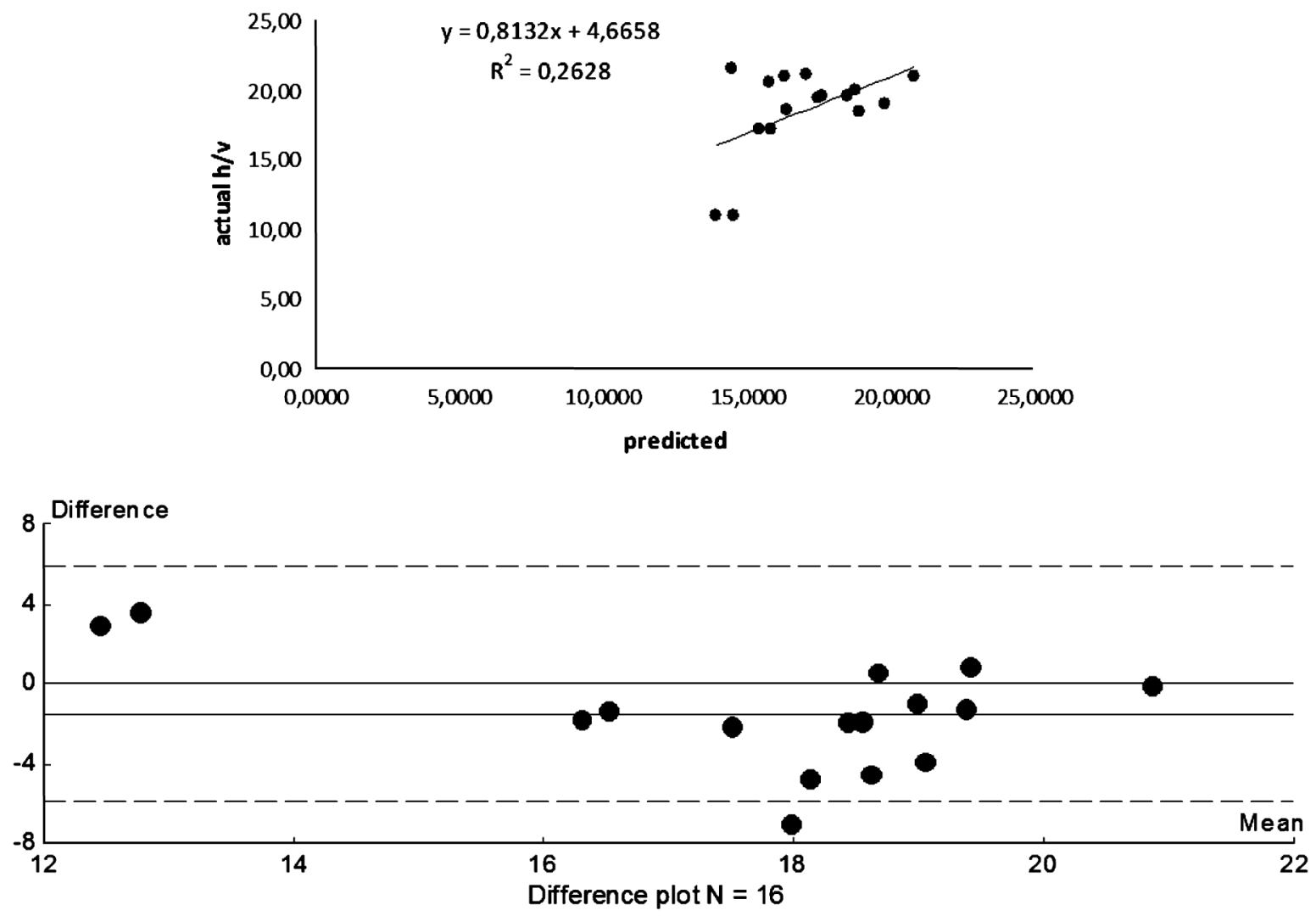

Mean difference : $-1,49$ [ $-2,96$ to $-0,0242]$

Fig. 2. Agreement between the model-derived 'optimal values of $h / \eta$ ratio predicted with Quemada's equation and actual value, showing that actual $\mathrm{h} / \eta$ is on the average slightly higher than theoretical $\mathrm{h} / \eta$. The correlation coefficient is $r=0.513$ $p<0.05$ 

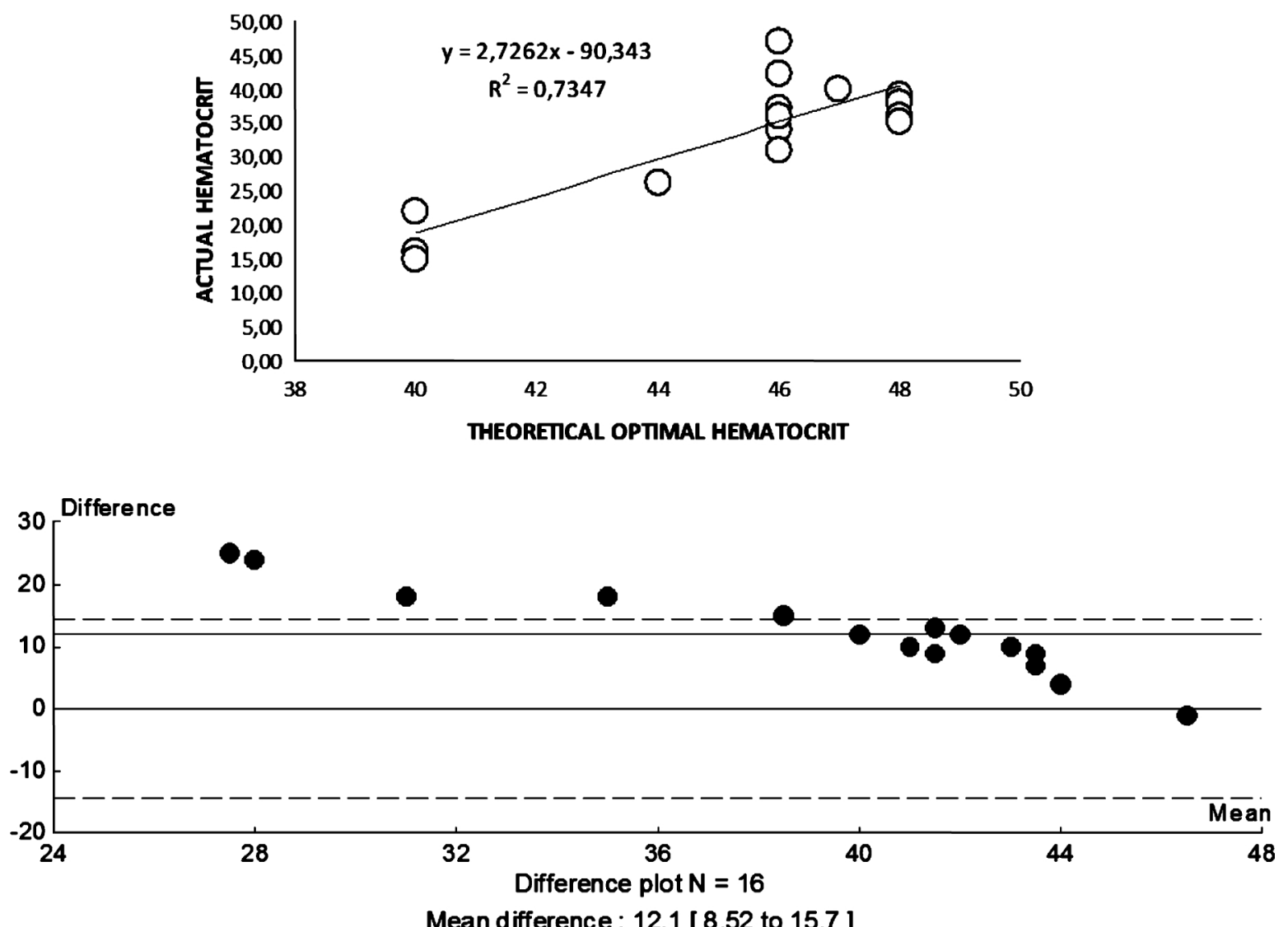

Fig. 3. Agreement between the model-derived 'optimal values of hematocrit predicted with Quemada's equation and actual value, showing that actual hematocrit is on much lower than its theoretical optimal value given by the model. The correlation coefficient is $r=0.857, p<0.01$.

\section{Discussion}

This study shows that the curve of theoretical optimal $h / \eta$ plotted vs hematocrit reconstructed with Quemada's equation provides a value of "optimal hematocrit" that is correlated to actual one and is in agreement with the prediction of optimal hematocrit given by Linderkamp's studies on glass tubes. Actual hematocrit is much lower than this 'optimal' value calculated with the model. Actual hematocrit is correlated to umbilical artery resistance, while optimal hematocrit is not. The discrepancy between ideal and actual hematocrit is negatively correlated to umbilical artery resistance index. This discrepancy is also strongly correlated with red cell rigidity and negatively correlated to whole blood viscosity. Red cell rigidity is in turn negatively correlated to the umbilical artery resistance index.

As we discussed in our previous paper on the same subject [6], it is difficult, for obvious ethical reasons, to measure fetal blood rheology without medical reasons for performing a cordocentesis. Therefore, our sample of fetuses is not a truly 'physiological' one and is selected after the fetal pathologies have been ruled out: this represents an important cause of methodological bias which seems difficult to overcome. However, we think that this approach provides a more direct evaluation of what happens in utero than the previous studies using cord blood at birth. Our measurements show that the study of cord blood of prematures at birth, as performed by the first investigators in this field $[1,3$, $4,7,8,12,14,16,17,21]$, is a reliable model for evaluating fetal rheology. However, we suggested in 
our previous paper that two major possibilities of artifacts exist for that method: (a) prematures are not 'normal' newborns and could be expected to have diseases which modify blood rheology; (b) labor and delivery are very stressful events which induce in the mother dramatic increases in blood viscosity. Moreover, for many physiological reasons, the newborn can no longer be considered as a fetus.

Concerning laboratory measurements, the MT90 falling ball viscometer [MT 90 Medicatest, F-86280 Saint Benoit] which has been largely used in our clinical studies also offers the advantage of minimal volume requirements (about $800 \mu 1$ ).

As reminded above, Linderkamp [18] determined an optimal hematocrit in fetal blood in narrow glass tubes that was around $40 \%$ in 500-pm tubes, around 52\% in 100-pm tubes, and around $60 \%$ in 50 -pm tubes. Our finding of a value at $45.31 \pm 0.71 \%$ is consistent with these studies. In addition, the fair correlation between theoretical and actual hematocrit shown on Fig. 3 suggests that this prediction of an ideal hematocrit makes sense, even if the body sets the actual hematocrit at a much lower value of $30.52 \pm 2.26 \%$.

Interestingly, the large gap between optimal and actual hematocrit is inversely correlated with arterial resistance, indicating that the higher the gap the lower resistance. This observation leads to think that the body sets hematocrit below ideal in order to minimize arterial resistance.

We previously reported that the hematocrit/viscosity ratio remains constant with no tendency to increase during intrauterine life, as a result of a combination of the various changes observed during this period, suggesting that there is in fetuses some degree of homeostasis of the rheologic determinants of fetal blood circulation during the intrauterine life. By contrast hematocrit gradually increases during the intrauterine life. However, in this sample, we find a stronger correlation between hematocrit and its predicted optimal value than between predicted and actual $h / \eta$ suggesting that in the case of fetuses the most closely regulated parameter can ben hematocrit rather than $h / \eta$.

In this respect the correlations shown on Fig. 5 may provide an explanation. Hematocrit seems to be lowered below its ideal value as an adaptative response to increased red cell rigidity, resulting therefore in a decrease in whole blood viscosity. This may explain the unexpected correlation shown on Fig. 6. This correlation may indicate that increased red cell rigidity induces vasodilation and thus decreases vascular resistance, but the lack of maturity of vasomotor regulation in fetal vascular bed makes this rather unlikely and this may reflect, on the opposite, that increased red cell rigidity induces a compensatory decrease in hematocrit that sets it below the ideal value. The exact feedback loop that may underlie such a regulation linking red cell rigidity to hematocrit is not clearly understood at present. In adults, removal of rigid red cells by the reticulo endothelial system and the spleen are a classical mechanism of 'viscoregulation' $[2,15]$ but whether it operates in fetus is not well known.

\section{Conclusions}

On the whole, this study shows that we can predict with Quemada's model an ideal hematocrit for fetal blood that is in agreement with previous physiological studies but that in vivo hematocrit appears to be lower than this ideal value. This lowering appears to be proportional to red cell rigidity and to vascular resistance in the umbilical artery, suggesting that there is a homeostatic regulation of hematocrit aiming at avoiding excess vascular resistance in fetal circulation.

\section{Acknowledgments}

The authors affirm that they have no disclosure of interest concerning the issue investigated in this paper. This study was presented as oral communication at the 18th European Conference on Clinical Hemorheology. June 2016, Lisbon. 


\section{References}

[1] M.A. Anwar, M.W. Rampling, S. Bignall and R.P. Rivers, The variation with gestational age of the rheological properties of the blood of the new-born, British Journal of Haematology 86 (1994), 163-168.

[2] O.K. Baskurt, The role of spleen in suppressing the rheological alterations in circulating blood, Clinical Hemorheology and Microcirculation 20(3) (1999), 81-188.

[3] P. Boulot, J.-F. Brun, C. Fons, A. El Bouhmadi, M.N. Hédon, J.L. Viala and A. Orsetti, The haemorheology of foetus studied by umbilical cord venepunctures in utero, Revista Portuguesa de Hemorreologia 5 (1991), 111-117.

[4] P. Boulot, J.-F. Brun, C. Fons, A. El Bouhmadi, M.N. Hédon, J.L. Viala and A. Orsetti, Caractéristiques du sang foetal prélevé in utero par cordocentèse, Revue Française de Gynécologie Obstétrique 86 (1991), 154-157.

[5] P. Boulot, F. Deschamps, G. Lefort, P. Sarda, P. Marès, B. Hédon, F. Laffargue and J.-L. Viala, Pure fetal blood samples obtained by cordocentesis: Technical aspect of 322 cases, Prenatal Diagnosis 10 (1990), 93-100.

[6] J.-F. Brun, P. Boulot, F. Frosi, F. Deschamps, B. Bachelard, C. Fons, I. Supparo, C. Mallard, J.-L. Viala and A. Orsetti, Study of some physiological aspects of blood rheology in fetuses by intrauterine cord venepunctures. Relationships with hemodynamic measurements, Clinical Hemorheology and Microcirculation 13 (1993), 215-226.

[7] P.C. Buchan, Evaluation and modification of whole blood filtration in the measurement of erythrocyte deformability in pregnancy and the newborn, British Journal of Haematology 45 (1980), 97-105.

[8] P.C. Buchan, Maternal and fetal blood viscosity throughout normal pregnancy, British Journal of Obstetrics Gynaecology 4 (1984), 343.

[9] J.W. Crowell and E.E. Smith, Determinant of the optimal hematocrit, Journal of Applied Physiology 22 (1967), $501-504$.

[10] L. Dintenfass, Blood viscosity, Hyperviscosity \& Hyperviscosaemia. Melbourne, MTP press, $1985,482$.

[11] J. Doffin, R. Perrault and G. Garnaud, Blood viscosity measurements in both extensional and shear flow by a falling ball viscometer, Biorheology 21(Suppl 1) (1984), 89-93.

[12] M.E. Foley, D.M. Isherwood and G.P. McNicol, Viscosity, haematocrit, fibrinogen and plasma proteins in maternal and cord blood, British Journal of Obstetrics and Gynaecology 85 (1978), 500-504.

[13] C. Fons, J.-F. Brun, I. Supparo, C. Mallard, C. Bardet and A. Orsetti, Evaluation of blood viscosity at high shear rate with a falling ball viscometer, Clinical Hemorheology and Microcirculation 13 (1993), 651-659.

[14] P. Gaehtgens and S. Schickendantz, Rheologic properties of maternal and neonatal blood, Bibliotheca Anatomica 13 (1975), 107-108.

[15] M.R. Hardeman, The pliant and ag(g)reeable erythrocyte, Clinical Hemorheology and Microcirculation 55(1) (2013), 7-14.

[16] N. Kuss, E. Bauknecht, C. Felbinger, J. Gehm, L. Gehm, J. Pöschl and P. Ruef, Determination of whole blood and plasma viscosity in term neonates by flow curve analysis with the LS300 viscometer, Clinical Hemorheology and Microcirculation 63 (2015), 3-14.

[17] O. Linderkamp, H.C. Sengenpeik, C.B. McKay and H.J. Meiselman, Rheological properties of blood in preterm and fullterm neonates. In: Hemorheological disorders in obstetrics and neonatalogy. Heilmann L, Buchan PC (Eds) Schattauer, 1984, pp. 83-91.

[18] O. Linderkamp, A.A. Stadler and E.P. Zilow, Blood viscosity and optimal hematocrit in preterm and full-term neonates in 50- to 500- $\mu \mathrm{m}$ tubes, Pediatric Research 32 (1992), 97-102.

[19] L. Pourcelot and P. Arbeille, Evolution de la circulation foeto-placentaire au cours de la grossesse normale et pathologique, Soir Echographie Gynecologie Obstetricale 30 (1982), 23-29.

[20] D. Quemada, Rheology of concentrated disperse systems. II. A model of non newtonian shear viscosity in steady flows, Rheologyca Acta 17 (1978), 632-642.

[21] W.H. Reinhart, S.J. Danoff, R.G. King and S. Chien, Rheology of fetal and maternal blood, Pediatric Research 19 (1985), 147-153.

[22] H. Schmid-Schönbein, E. Volger and H.J. Klose, Microrheology and light transmission of blood III: The velocity of red cell aggregate formation, Pflugers Archiv European Journal of Physiology 254 (1975), 299-317.

[23] H. Stark and S. Schuster, Comparison of various approaches to calculating the optimal hematocrit in vertebrate, Journal of Applied Physiology 113(3) (2012), 355-367. 